Revista General de Información y Documentación ISSN: $1132-1873$

\title{
Metodología para la confección de un Sistema de Información Histórico Fotográfico para la historia local en Extremadura. El ejemplo de Los Santos de Maimona
}

\author{
Penélope Rubiano Montaño ${ }^{1}$; Agustín Vivas Moreno²; María Victoria Nuño Moral $^{3}$
}

Recibido: 20 de febrero de 2019 / Aceptado: 5 de abril de 2019

Resumen. La presente investigación tiene como objeto establecer una metodología para la creación de un Sistema de Información Documental Fotográfico (SIDF) que nos permita el estudio de la historia local. Los recursos metodológicos empleados han sido varios: las técnicas documentales, que comprende la identificación de la imagen y su descripción documental a través de la adaptación de una normativa archivística, así como con la extracción de descriptores; las tecnologías de la información, mediante la elaboración de un tesauro que se inserta en un gestor documental automatizado, que es una herramienta que utiliza las tecnologías de la información y la comunicación para obtener más rendimiento de la aplicación; $y$, por último, los métodos analíticos, que son el análisis de las imágenes en todos sus aspectos (formales, físicos y conceptuales). Se ofrece como resultado un gestor documental que integra los recursos metodológicos mencionados como sostén de trabajos de la necesitada historia local. Todo ello es aplicado al estudio de los oficios de Los Santos de Maimona, un pueblo de la provincia de Badajoz. Consecuentemente, concluimos que la importancia de la fotografía como recurso documental para la elaboración de la memoria colectiva necesita de SIDF como procedimiento de búsqueda y recuperación de la información.

Palabras clave: Documentación fotográfica; Fotográfico; Historia local; Sistema de información documental.

\section{[en] Methodology for the preparation of a photographic historical information system for local history in Extremadura. The example of Los Santos de Maimona}

\author{
1 Archivo de Los Santos de Maimona \\ E-mail: peneloperubianomon@gmail.com \\ 2 Universidad de Extremadura. \\ E-mail: aguvivas@unex.es \\ 3 Universidad de Extremadura \\ E-mail: mvnunmor@unex.es
}

Abstract. The purpose of this research is to establish a methodology for the creation of a Photographic Documentary Information System (SIDF) that allows us to study local history. The methodological resources used have been several: documentary techniques, which include the identification of the image and its documentary description through the adaptation of archival regulations, as well as the extraction of descriptors; information technologies, through the elaboration of a thesaurus that is inserted in an automated document manager, which is a tool that uses 
information and communication technologies to obtain more performance from the application; and, finally, the analytical methods, which are the analysis of images in all their aspects (formal, physical and conceptual). It is offered as a result a documentary manager that integrates the aforementioned methodological resources as support of works of the needed local history. All this is applied to the study of the trades of Los Santos de Maimona, a town in the province of Badajoz. Consequently, we conclude that the importance of photography as a documentary resource for the elaboration of collective memory requires SIDF as a procedure for searching and retrieving information.

Keywords: Photographic documentation; Photographic; Local history; Documentary information system.

Sumario. 1. Introducción. 2. Recursos metodológicos para la confección del sistema de información. 3. El ejemplo de los oficios en las fotografías de Los Santos de Maimona. 4 Conclusiones. 5 Referencias Bibliográficas.

Cómo citar: Rubiano Montaño, P.; Vivas Moreno, A.; Nuño Moral, M.V. (2019) Metodología para la confección de un Sistema de Información Histórico Fotográfico para la historia local en Extremadura. El ejemplo de Los Santos de Maimona., en Revista General de Información y Documentación 29 (1), 241-259.

\section{Introducción}

El presente trabajo demuestra la importancia que tiene la fotografía para el análisis de la historia local y cómo, sometiéndola a un tratamiento adecuado, se convertirá en un documento esencial para cualquier tipo de estudio.

Son varias las causas que han hecho posible que nos decantáramos por un artículo de esta naturaleza. Por un lado nuestro interés hacia la historia local. Como más abajo tendremos ocasión de analizar, la fotografía es un documento de enorme valor para llevar a cabo configuraciones reflexivas sobre la microhistoria, esto es, la intrahistoria de los pueblos que representan fielmente el devenir del tiempo y sus estructuras. Otra de las causas has sido la recuperación del patrimonio fotográfico (Castellano Gámez, 1996: 90), en ocasiones perdido y otras abandonado y disperso $^{4}$ (Benavides Solís, 1995: 32), esperando tratamientos de carácter documental $^{5}$ (Cerdá Días, 2000: 369) que posibiliten la recuperación para todos ${ }^{6}$. En tercer lugar, la inexistencia de trabajos de este tipo en Extremadura, como

4 LIPOVETSKY habla de a la sociedad actual como "la cultura de la conservación posmoderna" y la define con tres paradojas: Cuanto más nos atrae lo efímero, más nos entusiasma el pasado. Entre lo efímero y el pasado (formas de percibir el tiempo) está el patrimonio (el tiempo como unidad histórica. Referencia a la Estética); Cuanto más se despliega el individualismo (autonomía subjetiva) más se evoca la vuelta de lo religioso. Exigencia de identidades regionales y nacionales (preocupación por la tradición); Cuanto mayor es el egocentrismo, más aumenta la conciencia de responsabilidad ecológica (Ecología).

5 El autor nos explica que los archivos deberían ser hoy un espacio objeto de atención e interés por parte de los ciudadanos, y sobre todo, a la medida de sus capacidades y necesidades. Sin embargo, se constata que dentro de los servicios de información, el archivo es el gran desconocido y por tanto, menos utilizado a diferencia de las bibliotecas.

6 El Consejo Internacional de Archivos (CIA) fue creado por iniciativa de la UNESCO. Ejecuta técnicamente parte del programa archivístico de la UNESCO además de servir de vínculo de relación entre los profesionales de todo el mundo. Da a conocer los archivos adaptando sus programas y servicios, especialmente los modos y los medios de sus canales de comunicación y adecuando los sistemas de descripción y recuperación de la información a las necesidades informativas de los usuarios. 
veremos en el siguiente apartado. Y, por último, la consideración de la fotografía como un documento social, dado que a partir de ella podemos obtener resultados sobre acontecimientos sociales, políticos, culturales, etc.

Todo ello nos ha llevado a plantearnos los siguientes OBJETIVOS:

1. El primero consiste en crear un corpus documental fotográfico, mediante la localización y recuperación de todas las fotografías relacionadas con una cuestión determinada de la historia. En nuestro caso serán fotografías de los oficios que se realizaban en Los Santos de Maimona en el s. XX, a las que, posteriormente, someteremos a una descripción documental, con la que obtengamos todos los datos de interés que puedan contener.

2. El segundo objetivo ha sido elaborar un Sistema de Información Histórico Fotográfico (SIHF) que nos permita trabajar con dichos documentos, utilizando para ello una serie de técnicas documentales que cataloguen las fotografías. A continuación, se han almacenado en un gestor documental automatizado (que veremos más adelante) que nos facilita la recuperación de las mismas mediante el empleo de las tecnologías de la información y la comunicación.

3. Y el tercer, y último, objetivo analizar históricamente a partir de las fotografías; éste ha sido posible gracias al gestor documental creado ad hoc.

El eje que vertebra el análisis presentado es la creación de un Sistema de Información Histórico (SIH). Son numerosos los autores que definen estos sistemas (Moreiro González, 1995: 137), (Codina Bonilla, 1994: 433), (Ruiz Rodríguez, 1995: 103 - 184), (García Marco, 2017).Un SIH puede ser considerado como un instrumento operativo que convierte los documentos históricos (en nuestro caso las fotografías históricas), debidamente conservados, en información y que, como resultado de los diferentes tratamientos documentales, son utilizados por el investigador para la producción de nueva información.

Como paso previo a la realización del estudio que acabamos de plantear, ha resultado imprescindible llevar a cabo un análisis sobre distintos aspectos de interés; en concreto, sobre la situación de la fotografía en Extremadura y la importancia de la historia local.

Se han analizado las fuentes documentales fotográficas existentes en la región, así como el método de trabajo que utilizan. Paralelamente, se ha realizado un estudio sobre la bibliografía existente en esta materia.

A continuación, mostramos una tabla con algunas de las Unidades de Información extremeñas que disponen de fondos fotográficos (tabla 1), y que nos han servido para confeccionar nuestro SI. 
Tabla 1. Unidades de Información en Extremadura (elaboración propia).

\begin{tabular}{|c|c|}
\hline UNIDADES DE INFORMACIÓN & $\mathrm{N}^{\circ}$ DE DOCUMENTOS FOTOGRÁFICOS \\
\hline Archivo de la Asamblea de Extremadura & $\begin{array}{l}3.299 \text { fotos en papel, } 12 \text { tiras de negativos, } 30 \\
\text { diapositivas y } 126.580 \text { fotografías digitales. }\end{array}$ \\
\hline Archivo Central de la Junta de Extremadura & Sin contabilizar el número de imágenes \\
\hline Archivo Histórico Provincial de Badajoz & 1.595 fotografías \\
\hline Archivo Histórico Provincial de Cáceres & $\begin{array}{l}4.725 \text { fotos: } 1.782 \text { son documentos fotográficos y } \\
2.943 \text { son fotos aéreas y en positivo, alguna en } \\
\text { negativo y otras en diapositivas }\end{array}$ \\
\hline $\begin{array}{l}\text { Archivo fotográfico del Centro de Información } \\
\text { Cartográfica y Territorial de Extremadura }\end{array}$ & $\begin{array}{l}\text { Más de } 10.000 \text { fotogramas en papel y más de } \\
20.000 \text { fotogramas en digital. }\end{array}$ \\
\hline Centro de Estudios Agrarios & $\begin{array}{l}701 \text { fotografías de Colección IRYDA, } 1.663 \text { fotos } \\
\text { de colección CAL, } 673 \text { de la colección SEA. }\end{array}$ \\
\hline $\begin{array}{l}\text { Archivo de la Diputación Provincial de } \\
\text { Badajoz }\end{array}$ & $\begin{array}{l}36.374 \text { unidades fotográficas (positivos, negativos y } \\
\text { diapositivas). }\end{array}$ \\
\hline $\begin{array}{l}\text { Archivo de la Diputación Provincial de } \\
\text { Cáceres }\end{array}$ & $\begin{array}{c}294 \text { fotografías en inventario y } 800 \text { en expedientes } \\
\text { de archivo. }\end{array}$ \\
\hline Archivo Histórico Municipal de Mérida & $\begin{array}{l}2.120 \text { fotografías en papel, } 62 \text { diapositivas, } 7937 \\
\text { fotos digitales y } 1 \text { millón imágenes fondo } \\
\text { documental. }\end{array}$ \\
\hline Archivo Municipal de Trujillo & 1.089 fotografías digitalizadas. \\
\hline $\begin{array}{l}\text { Archivo de la Universidad Pública de } \\
\text { Extremadura }\end{array}$ & Más de 1.400 imágenes en jpeg. \\
\hline $\begin{array}{l}\text { Archivo del Movimiento obrero de } \\
\text { Extremadura }\end{array}$ & 257 fotografías en papel y 6.487 en digital. \\
\hline Archivo de prensa del periódico HOY & $\begin{array}{l}\text { Miles de fotografías: desde } 1996 \text { están digitalizadas } \\
\text { y las anteriores en papel. }\end{array}$ \\
\hline $\begin{array}{l}\text { Archivo de la Confederación Hidrográfica del } \\
\text { Guadiana }\end{array}$ & $\begin{array}{l}\text { Se desconoce el número exacto de fotografías y } \\
\text { predominan en papel. }\end{array}$ \\
\hline Biblioteca Regional de Extremadura & $\begin{array}{l}\text { Alrededor de } 100.000 \text { fotografías en papel y } 5.000 \\
\text { negativos en placas de cristal y acetato. }\end{array}$ \\
\hline Museo Nacional de Arte Romano de Mérida & $\begin{array}{l}262 \text { placas de cristal y } 587 \text { negativos en gran } \\
\text { formato. }\end{array}$ \\
\hline $\begin{array}{l}\text { Museo Extremeño e Iberoamericano de arte } \\
\text { contemporáneo (MEIAC) }\end{array}$ & $\begin{array}{l}\text { Aproximadamente } 800 \text { fotografías que están en los } \\
\text { archivos personales de los artistas. }\end{array}$ \\
\hline $\begin{array}{c}\text { Gabinete de prensa de la Diputación de } \\
\text { Badajoz }\end{array}$ & $\begin{array}{l}14.000 \text { negativos de } 35 \mathrm{~mm} \text { en blanco y negro y } \\
\text { color; y } 3.000 \text { diapositivas de } 135 \mathrm{~mm} \text { en color. }\end{array}$ \\
\hline
\end{tabular}

A partir de esta realidad, se ha constatado no solo la escasez de organismos públicos con documentos fotográficos, sino también la carencia de un organismo central que gestione estos documentos; a todo ello, se le une la dispersión de fondos fotográficos en manos de instituciones y particulares. Otra de las cuestiones que se evidencia es que existe un desierto normativo que impide regular estos archivos, además de la ausencia de herramientas específicas para trabajar con las 
fotografías. Por lo tanto, observamos una falta de reconocimiento de la imagen como documento histórico.

En cuanto a la bibliografía existente en Extremadura, se observa que algunos escritores han intentado hacer una historia de la fotografía (Cano Ramos, 2014), como es el caso de Matilde Muro (Muro Castillo, 2000), (Muro Castillo, 2009) o de Antonio Regalado (Regalado Guareño, 2013); otros han utilizado la fotografía para argumentar y complementar trabajos de diversas temáticas ${ }^{7}$, como Ángel Manuel Felicísimo Pérez ${ }^{8}$ (Felicísimo Pérez; Cuartero Sáez, 2018); o bien, utilizan la imagen como argumento principal en sus estudios, tal y como refleja José Soto Vázquez ${ }^{9}$ (Soto Vázquez, 2011: 5 - 52), (Soto Vázquez, 2009: 245 - 263) o Antonio Navarreño Mateos (Navarreño Mateo; Pérez Rodríguez, 1985).

Al margen de estos autores, también existen catálogos de fotografías que estarían mejor en el apartado de fuentes documentales que en el de bibliografía; tal es el caso del de la Diputación de Badajoz sobre Fernando Garrorena Arcas o exposiciones fotográficas ${ }^{10}$; o libros con fotografías de las obras de autores que han sobresalido en diversas áreas del conocimiento (pintores, escultores, etc.), como es el caso de los hermanos Tinoco ${ }^{11}$.

Llegados a este punto, se ha considerado imprescindible analizar la importancia de la historia local, ya que la fotografía es un instrumento para el análisis de la misma.

No es necesario indicar que la historia local resulta ser imprescindible para entender quiénes somos, así como para vaticinar nuestro futuro. Conocer y transmitir la historia de un pueblo nos ayudará a percibir los rasgos que nos identifican y nos hacen diferentes de los demás ${ }^{12}$ (Pacheco Valero, 2003). Nos permitirá posicionarnos ante el mundo y tener una identidad cultural propia. Paralelamente, será posible visualizar los paralelismos existentes entre los fenómenos nacionales, regionales y locales (Lacomba, 2008), permitiendo mostrar los matices o excepciones que existen en nuestra localidad con respecto al resto de la comunidad o nación (Serna; Pons, 1993: 131).

Para analizar la historia local es importante entrar en contacto directo con todo tipo de documentos, monumentos y otras fuentes de conocimiento histórico. En

7 Algunos de estos trabajos son: Vuelo 3D interactivo sobre Extremadura. Junta de Extremadura. Agencia Extremeña de la Vivienda, el Urbanismo y el Territorio. Y Guijo de Granadilla. Cien años de imágenes. Ayuntamiento de Guijo de Granadilla, 2007.

8 Los autores muestran cuarenta poblaciones y sus cambios reflejados en fotografías aéreas antiguas y recientes.

9 El autor hace una recuperación del material fotográfico escolar de Ezequiel Fernández Santana, maestro y cura de Los Santos de Maimona. Su trabajo pretende mostrar el estado en que se encontraban las escuelas de niños de Los Santos de Maimona en el primer tercio del siglo XX.

10 José María Ballester Olivera, Guillermo Gabardino Herrera y Miguel Ángel Rodríguez Plaza realizan una exposición de fotografía titulada Tres miradas distintas: fotografías, en el Museo de Cáceres, en los meses de junio y agosto del año 2006.

11 El Museo de Bellas Artes de Badajoz publicó en el año 2007 El taller de los hermanos Tinoco: exposición 26 de abril - 26 de junio de 2007.Los hermanos Tinoco son Mauricio, que fue un escultor formado en Sevilla, $\mathrm{y}$ Alejandro, que practicó la pintura; ambos proceden de Los Santos de Maimona y en el citado Museo de Badajoz se conservan dos lienzos de este último.

12 Irina Pacheco Valero realizó una tesis doctoral con opción al título académico de Máster en Ciencias de la Educación Superior en la Mención de Docencia Universitaria e Investigación Educativa en la Ciudad de la Habana, relacionada con el conocimiento de la identidad cultural. 
nuestro caso concreto, la utilización documental de las fuentes gráficas (fotografías) ha permitido conocer en profundidad un aspecto determinado de la historia.

Se ha tratado la fotografía como una fuente documental de primer orden. Y esto, unido a la recuperación de aspectos cotidianos (Díaz Barrado, 1998: 41) de la localidad, ha posibilitado conocer a fondo la historia local a través de ella (Lara López, 2005: 2).

En definitiva, se apuesta por la utilización de la fotografía como principal fuente de información documental (Bayod Camarero, 2005: 2) para el estudio de la historia local, complementándola con el resto de soportes documentales.

\section{Recursos metodológicos para la confección del sistema de información}

A continuación se exponen cuáles son los recursos metodológicos que se han utilizado para la confección del SIHF. Para ello, en la figura 1 representamos la metodología empleada. Como se puede comprobar en la tabla, hemos empleado una serie de herramientas que nos han permitido establecer y llevar a cabo un método de trabajo con el que conseguir cada uno de los objetivos planteados en nuestro trabajo de investigación:

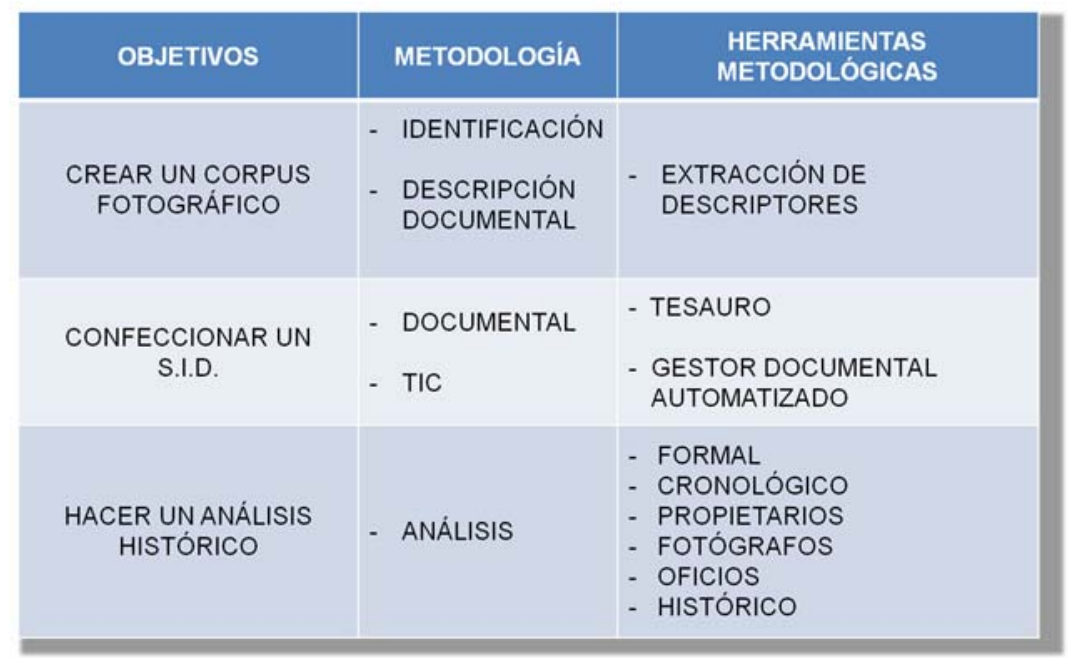

Figura 1. Metodología para la confección de un SI (elaboración propia).

- Para la creación del corpus fotográfico se ha empleado una metodología documental consistente en el rastreo, identificación y localización de las fotografías y su posterior descripción. Para llevarlo a cabo, se han extraído de las imágenes una serie de descriptores que las identifiquen.

- Para logar el segundo objetivo, la elaboración de un sistema de información documental, la metodología utilizada es la documental y las tecnologías de la información; y las herramientas que se han necesitado han sido un tesauro y un gestor documental automatizado. 
- Y, por último, el objetivo del análisis histórico se ha realizado mediante el análisis de las fotografías: análisis formal, cronológico, de propietarios, de los fotógrafos, de los oficios que representan las imágenes y, finalmente, el análisis histórico.

Todo esto se detalla de manera exhaustiva en los siguientes epígrafes.

a. La identificación y descripción documental para la creación de un corpus fotográfico.

Esta metodología consiste en el rastreo, localización y obtención de las fotografías necesarias para nuestra investigación histórica, y la consiguiente elaboración de un corpus fotográfico. Hemos tenido ciertas dificultades para identificar y localizar las fotografías que precisábamos para realizar nuestro trabajo de investigación en Los Santos de Maimona.

En primer lugar porque, a nivel local, no existe ningún organismo oficial, ni público ni privado, donde se conserven fotografías o algún centro encargado del tratamiento de las mismas. Únicamente hemos encontrado un libro sobre fotografías locales de Lucio Poves Verde, titulado Estampas para el recuerdo (Poves Verde, 1998), aunque no se trata de un trabajo científico, sino de una recopilación de imágenes antiguas. También existen publicaciones de pintores, escultores y otros artistas locales, realizados sin una metodología científica.

Las fotografías se encuentran dispersas por la localidad, en manos de particulares que atesoran un gran número de imágenes de gran valor informativo, pero sin normalizar.

Por último, el principal problema ha sido la desconfianza y el recelo de tales particulares a facilitárnoslas.

Por todos estos motivos, hemos logrado identificar a las personas que desempeñaban oficios en la localidad (a las que hemos denominado propietarios), y les hemos solicitado las fotografías que atestiguaran su puesto de trabajo. Consideramos propietario tanto a la persona que hace la fotografía como a la que la conserva y custodia.

En total, hemos conseguido novecientas cuarenta fotografías de diversos propietarios:

- Por un lado, están las personas físicas, que han sido identificadas con nombres, apellidos $\mathrm{y}$, cuando ha sido posible, con un cualificador que menciona su carácter profesional o el parentesco con los verdaderos propietarios de las fotografías, y que va entre paréntesis. El número de fotografías que aportan entre todos son setecientos ochenta y ocho, el 84.15 $\%$ de la colección.

- También contamos con fotografías cedidas por instituciones, tanto públicas como privadas. Entre las públicas están dos colegios locales que aportan seis imágenes (un $0.64 \%$ del total) y el Archivo Municipal que aporta tres $(0.32$ $\%)$. En cuanto a las instituciones privadas, son tres las que ingresan 
fotografías a nuestra investigación, sumando un total de veintiuna imágenes, es decir, un $2.23 \%$ del total.

- Hay un elevado número de fotografías provenientes del libro de Lucio Poves (que ya hemos mencionado), fotografías que por su valor histórico hemos querido rescatar, y que en su día cedieron algunos propietarios para la creación del mismo. Forman un total de ciento veintidós instantáneas, es decir, el $12.98 \%$ de nuestra colección.

En definitiva, contamos con ciento veintiún propietarios, de los que ciento doce son personas particulares y el resto, es decir nueve, son instituciones.

En consecuencia, la existencia de diversas procedencias ocasiona que debamos hablar de colección fotográfica y no de fondo fotográfico, donde la génesis documental es múltiple y heterogénea.

La descripción de cada unidad documental ha sido la siguiente:

Tabla 2. Ficha fotográfica (elaboración propia).

\begin{tabular}{|c|c|c|}
\hline ÁREAS & SUBÁREAS & DESCRIPCIÓN \\
\hline \multirow{8}{*}{$\begin{array}{l}1 \text { ÁREA DE } \\
\text { IDENTIFICACIÓN }\end{array}$} & Código de referencia. & $\begin{array}{l}\text { Es la signatura de la unidad } \\
\text { documental, y será un código } \\
\text { de letras y números }\end{array}$ \\
\hline & $\begin{array}{l}\text { Título: } \\
-\quad \begin{array}{l}\text { Mención } \\
\text { responsabilidad. }\end{array}\end{array}$ & $\begin{array}{l}\text { Estará relacionado con el } \\
\text { contenido de la foto, será } \\
\text { conciso e irá en lenguaje } \\
\text { natural. Será el productor y el } \\
\text { fotógrafo. }\end{array}$ \\
\hline & Fechas. & $\begin{array}{l}\text { Momento en el que fue tomada } \\
\text { la foto. }\end{array}$ \\
\hline & $\begin{array}{l}\text { Volumen y soporte: } \\
-\quad \text { Tipo de imagen: }\end{array}$ & $\begin{array}{l}\text { Si la foto está en negativo o en } \\
\text { positivo. }\end{array}$ \\
\hline & - $\quad$ Tipo de soporte: & $\begin{array}{l}\text { Tipo de materia física sobre la } \\
\text { que está fijada la imagen: } \\
\text { papel o cristal. }\end{array}$ \\
\hline & - $\quad$ Tono de la imagen: & $\begin{array}{l}\text { Característica cromática de la } \\
\text { foto: blanco y negro o en color. }\end{array}$ \\
\hline & - $\quad$ Tipo de plano: & $\begin{array}{l}\text { Consiste en realizar una } \\
\text { descripción del contenido } \\
\text { icónico de la foto, que le da } \\
\text { sentido particular a la misma. }\end{array}$ \\
\hline & $\begin{array}{l}\text { Género de la } \\
\text { fotografía: }\end{array}$ & $\begin{array}{l}\text { Son los diferentes temas } \\
\text { tratados en la foto. }\end{array}$ \\
\hline 2 ÁREA DE CONTEXTO & Nombre del propietario. & $\begin{array}{l}\text { Contiene información del } \\
\text { origen y custodia de la imagen. }\end{array}$ \\
\hline $\begin{array}{l}3 \text { ÁREA DE CONTENIDO } \\
\text { Y ESTRUCTURA }\end{array}$ & Alcance y contenido. & $\begin{array}{l}\text { Esta área está fusionada con el } \\
\text { área de título, aunque son } \\
\text { distintos. Por este motivo los } \\
\text { títulos son más amplios. }\end{array}$ \\
\hline $\begin{array}{l}4 \text { ÁREA DE } \\
\text { CONDICIONES DE }\end{array}$ & $\begin{array}{l}\text { Características físicas y } \\
\text { requisitos técnicos. }\end{array}$ & $\begin{array}{l}\text { Situación física en las que se } \\
\text { encuentra la foto que vamos a }\end{array}$ \\
\hline
\end{tabular}




\begin{tabular}{|l|l|l|}
\hline $\begin{array}{l}\text { ACCESO Y } \\
\text { UTILIZACIÓN }\end{array}$ & $\begin{array}{l}\text { describir y su estado de } \\
\text { conservación. }\end{array}$ \\
\hline $\begin{array}{l}\text { 5 ÁREA DE } \\
\text { DOCUMENTACIÓN }\end{array}$ & $\begin{array}{l}\text { Indica la existencia de copias } \\
\text { de las unidades que se están } \\
\text { describiendo. }\end{array}$ \\
\hline 6 ÁREA DE NOTAS & $\begin{array}{l}\text { Contiene información especial } \\
\text { y otra que no ha podido } \\
\text { incluirse en ninguna otra área. }\end{array}$ \\
\hline 7 ÁREA DE CONTROL & $\begin{array}{l}\text { Información relativa a la } \\
\text { descripción archivística. }\end{array}$ \\
\hline
\end{tabular}

Además de la ficha de análisis, se necesita crear un lenguaje documental que nos permita tanto identificar el contenido de las imágenes y almacenarlas de forma inequívoca, como recuperar dichas fotografías de la manera más eficaz y rápida posible.

Para ello, se han establecido una serie de descriptores ${ }^{13}$ (Pinto Molina, 1991); estos nos han facilitado el acceso a los fondos, convirtiéndose en puntos de acceso $^{14}$ (Valle Gastaminza, 1999: 16).Dicho lenguaje elimina la ambigüedad al dotar al usuario y al analista de un código único. Para la descripción de las fichas, se han usado cuatro tipos de descriptores ${ }^{15}$ y dado que el objetivo es crear un lenguaje normalizado, se ha recurrido a descriptores admitidos y no admitidos ${ }^{16}$.

\section{b. Las tecnologías de la información y la comunicación (TIC) para confección de un Sistema de Información Histórico Fotográfico.}

Como se ha esbozado anteriormente, los SI están especializados en la explotación de información cognitiva, cuyo fin es el de facilitar a los usuarios el acceso al conocimiento (Codina Bonilla, 1994: 433). La principal función de nuestro SI, ha sido dar respuesta a las necesidades informativas que se originan en el desarrollo de un trabajo de investigación y dejarlo abierto a posibles actualizaciones, ampliaciones y búsquedas de información aleatoria, tanto por las características informativas que almacene el sistema ${ }^{17}$, como por las herramientas documentales que se incluyen.

13 Estos descriptores nos permitirán hacer un tesauro para la recuperación de la documentación del Sistema de Información Histórico Fotográfico, ya que son una serie de palabras normalizadas que forman parte del sistema de análisis de contenido.

14 Con los descriptores recuperaremos los documentos, y para ello es imprescindible un análisis documental. El proceso de análisis comenzará por la lectura/observación, en nuestro caso, de la fotografía; seguiremos por la interpretación y concluiremos con la selección de significados que, una vez expresados en lenguaje textual, podrán ser normalizados mediante un lenguaje documental

15 Emplearemos los descriptores: onomásticos, que se aplican a nombres de personas y familias; los de entidad, que se aplican a un organismo o grupo de personas conocidos por un nombre determinado; los de materia, que son sustantivos o expresiones sustantivadas con una fuerte carga informativa que reflejan el contenido de los documentos; y por último los descriptores geográficos, que son los nombres propios de lugares a los que se hace referencia en los documentos.

16 Nos ayudaremos, en todo momento del Manual de indización para archivos ${ }^{16}$ editado y corregido por Rafael Aquino Guerra.

17 El objetivo de tales sistemas no será otro que el de resolver las necesidades documentales de los usuarios de la información histórica, y convertir esos documentos en información que es utilizada por el investigador para producir otra nueva. Para ello, es necesario tener esa documentación debidamente conservada, como principal pieza de esta cadena documental. 
La tipología de documentos con el que se va a trabajar son fotografías y, a su vez, esta documentación posee un carácter histórico, por lo que el SI se ha incluido dentro de los SIHF.

La primera metodología de trabajo que hemos empleado para realizar este SI, ha sido la documental, es decir que hemos confeccionado un tesauro, que es una herramienta de control terminológico basada en conceptos. Estos, son representados por términos seleccionados que evidencian ese control terminológico. Con ello se busca neutralizar la sinonimia y la polisemia, ambas características inherentes al lenguaje natural, que dificultan la precisión de la indización y recuperación de la información, funciones básicas de los tesauros ${ }^{18}$.

Dicho tesauro se ha incorporado al gestor, con tres objetivos fundamentales ${ }^{19}$ : el primero es enriquecer la funcionalidad de la estructura del tesauro a partir de la hipertextualidad, lo que se traduce en el establecimiento de hipervínculos entre todos los elementos: descriptores, no descriptores, etcétera, y las distintas partes del tesauro. En segundo lugar, se pretende reducir los costes de actualización y mantenimiento que se puedan realizar en un futuro. Y por último, permitir la posible aplicación de medidas de reutilización e interoperabilidad en el momento de planificar y construir los tesauros. Con ello, se posibilita el aprovechamiento y enriquecimiento de la información conceptual y lingüística ya generada para otros recursos.

Además del tesauro, otra de las herramientas que se ha utilizado para elaborar el SIHF ha sido un gestor documental automatizado, elaborado con una metodología basada en las tecnologías de la información y la comunicación (TIC) y basada en dos pilares fundamentales:

a) Una base fotográfica documental, recopilada a través de diversas fuentes. Las fotografías aportadas se han catalogado, datado e interpretado y han servido como base de la investigación. Las fotografías se han incluido en un gestor avanzado, que facilita el empleo de las mismas. A su vez, está formado por:

o Una base de datos principal, compuesta por tablas y las relaciones entre ellas, de las que destaca la tabla de archivo, que recoge los datos principales de la base documental de fotografías. A partir de la tabla principal, se distribuyen otras tablas secundarias que aportan valor a las fotografías a través de datos relevantes como soporte, tamaño, descriptores... Todo ello configura un sistema bastante elaborado $\mathrm{y}$ eficiente de datos.

18 Los tesauros son herramientas construidas para el auxilio tanto de los profesionales de la información como de los usuarios finales. Es una estructura semántica, creada a partir de los descriptores empleados para la normalización de los términos de la descripción fotográfica.

19 El impacto tecnológico del entorno digital ha afectado por igual a recursos, herramientas y comportamiento del usuario en relación a la representación y recuperación de información. Esta influencia abre nuevas posibilidades en cuanto a las pautas de diseño, elaboración, gestión y uso de las herramientas utilizadas para la representación y recuperación de información. Desde esta perspectiva, autores como López-Huertas (1997), De la Cueva Martín (2000), Shiri y Revie (2000) o Qin y Paling (2001) entre otros, han empezado a perfilar los aportes del entorno digital a los tesauros. 
o Una aplicación web, que es el interfaz ${ }^{20}$ entre la base de datos fotográfica y las peticiones de los usuarios. Se encarga de filtrar los datos, elaborar informes y mostrar información relevante según los criterios de búsqueda aplicados en cada momento. Así mismo, también se encarga del mantenimiento de la base de datos principal de una forma más visual, estableciendo unas acciones básicas sobre los registros, denominado Create, Read, Update and Delete (CRUD) (figura 2).

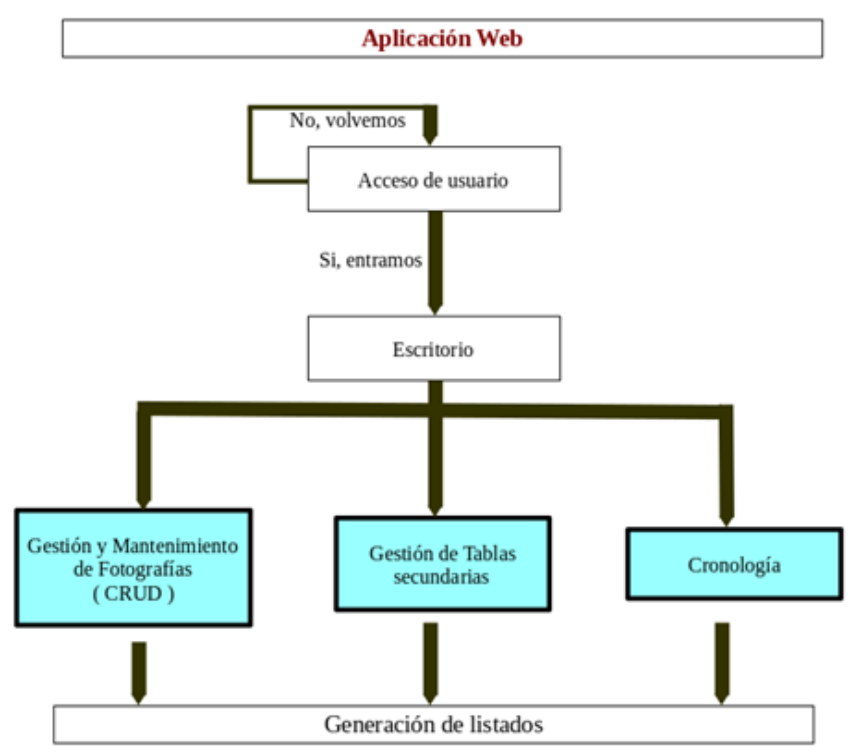

Figura 2. Estructura de la aplicación web (elaboración propia).

c. El análisis de las imágenes para la confección análisis histórico

Una vez elaborada la ficha y creado el SIHF, ya podemos someter nuestra muestra a un estudio. Para ello hemos realizado una metodología de análisis de las imágenes, extrayendo del gestor documental los datos que queremos estudiar.

Este análisis histórico ha servido para poder investigar los diferentes aspectos vinculados a la historia local y analizar individualmente cada una de las fotografías. Sin embargo, el análisis documental se ha utilizado de cara a la creación de colecciones e inventarios. De este modo, y basándonos en nuestro sistema documental automatizado, se ha obtenido información sobre distintos aspectos de las fotografias:

20 La interfaz de usuario es el medio con que el usuario puede comunicarse con una máquina o dispositivo, y comprende todos los puntos de contacto entre el usuario y el dispositivo. Normalmente suelen ser fáciles de entender y fáciles de accionar, aunque en el ámbito de la informática es preferible referirse a que suelen ser "amigables e intuitivos". 
- Aspectos formales. Han proporcionado información sobre sus características físicas como son:

o el tipo de imagen: de la totalidad de la muestra, el $99 \%$ son positivos (novecientas veintisiete fotografías), y tan solo un $1 \%$ están en negativo (trece fotografías).

o el tipo de soporte: solo contamos con un $1 \%$ de imágenes en cristal (trece fotografías), mientras que el soporte principal ha sido el papel, con novecientas veintisiete instantáneas (99\%).

o el tipo de tono: predominan las fotografías en blanco y negro con el $93 \%$ del total (ochocientas setenta y cinco imágenes), mientras que en color solo contamos con un $7 \%$, es decir sesenta y cinco fotografías.

o el tipo de plano: consiste en hacer una descripción del contenido de las fotografías. Para ello, las hemos dividido en varios tipos como el plano general, de las que hay quinientas setenta y dos imágenes (61\%); el plano entero, con ciento ochenta y cuatro instantáneas (20\%); el plano medio, con ciento cuarenta y cuatro (61\%); el plano detalle, con veintisiete $(3 \%)$; y, por último, de primerísimo primer plano, con trece (el $1 \%$ ) del total.

o el género: los temas que más se han tratado en las fotografías estudiadas han sido los retratos en grupo, con cuatrocientas sesenta y dos fotografías (49\%); seguidos por los temas militares/guerras, con ciento veintiún (13 $\%$ ); posteriormente de paisaje rural, con ciento siete (11\%); y finalmente los retratos, con ochenta y nueve $(9 \%)$. Los demás ocupan un porcentaje menos significativo dentro de nuestra muestra.

o el estado físico de conservación: reconocemos el buen estado de las imágenes porque setecientas dos del total lo indican, frente a ochenta y seis que están deterioradas, treinta y ocho rotas y treinta y siete distorsionadas. Las demás se encuadran dentro de un pequeño porcentaje, donde las podemos encontrar coloreadas, amarillentas y frágiles.

o y el tamaño de la fotografía: para tomar medidas de las imágenes hemos aplicado la longitud (en cm) del ancho por el largo, obviando los milímetros. No encontramos un tamaño estándar, sino una profusión de medidas que abarca desde los tres hasta los treinta cms. La mayoría (trescientas sesenta y siete) son de tamaño desconocido debido a que los propietarios las conservaban digitalizadas, sin medirlas. Le siguen las de diez centímetros (ciento treinta), las de siete $\mathrm{cm}$ (setenta y siete) y las de ocho (setenta y cinco).

- Aspectos cronológicos. Han permitido analizar las franjas temporales que deseamos investigar en cada momento. Las hemos agrupado por décadas y comprobamos que el aumento de las fotografías recopiladas es mayor a medida que avanzan las décadas. De las cuatro imágenes de la década de 1900 hay una progresión paulatina hasta las doscientas sesenta y nueve de 
los años 60, disminuyendo en la década de $\operatorname{los} 70$ a ochenta y dos instantáneas.

- Datos sobre los propietarios de las imágenes que forman la colección (un total de ciento veintiséis), y su incidencia en el oficio que representa la fotografía, tal y como hemos explicado más arriba.

- Datos sobre los fotógrafos o autores de las imágenes recopiladas, que son setenta en total. Abriendo un apartado para los que no hemos podido identificar, y denominándolos como desconocidos ${ }^{21}$.

- Datos sobre los oficios encontrados en las fotografías. Tenemos setenta y cuatro tipos de trabajos, que hemos aglutinado en doce sectores productivos genéricos, es decir en doce campos semánticos que les aportan cohesión a todos ellos y un vínculo en común. Para estudiarlos, siempre hemos seguido la misma estructura: explicar brevemente en qué consiste dicho trabajo, hacer un estudio cronológico del mismo y otro de la relación entre los oficios y los propietarios.

- Y por último, datos históricos, donde se especificarán aquellos temas que son relevantes para el análisis histórico y que son susceptibles de exámenes particulares. Nosotros los hemos englobado en razón de su importancia en:

o Temas naturales o principales: que son aquellos que consideramos que para que se estudie algo sobre la localidad es fundamental recurrir a nuestro trabajo, como es el caso de la agricultura, y de las cuestiones relacionadas con el arte, la cultura y la educación.

o También tendremos temas preferentes o secundarios, que aunque no son tan principales, sí que son importantes para conocer algunas cuestiones locales, como las profesiones artesanales y manuales, y los relacionados con la alimentación, comercio e industria.

o Y, finalmente, otros temas poco relevantes pero que puedan usarse para aseverar o argumentar alguna cuestión, como del deporte, la ropa, el urbanismo, etcétera.

\section{El ejemplo de los oficios en las fotografías de Los Santos de Maimona}

Todo este SI se ha adaptado al estudio de una cuestión determinada: el análisis de los oficios/trabajos que se realizaban en la localidad de Los Santos de Maimona (Badajoz) a través de la fotografía, desde principios del siglo XX hasta la Democracia (1975).

La figura 3 muestra cómo, todo lo explicado anteriormente, se encuentra inserto y compactado en el SIHF elaborado ad hoc. Tanto las herramientas de descripción, como el tesauro, el gestor documental automatizado y el análisis pormenorizado de

21 Contamos con setecientos cincuenta y dos imágenes con fotógrafos desconocidos, lo que supone $80 \%$ del total. Esta circunstancia no es exclusiva de la localidad de Los Santos de Maimona. Hay autores como Matilde Muro Castillo, Publio López Mondejar e incluso la colección fotográfica de la Biblioteca Nacional de Madrid, a los que les sucede lo mismo con las fotografías que conservan del s. XX. 
las imágenes, forman parte de una única herramienta que ha permitido realizar todo el análisis.

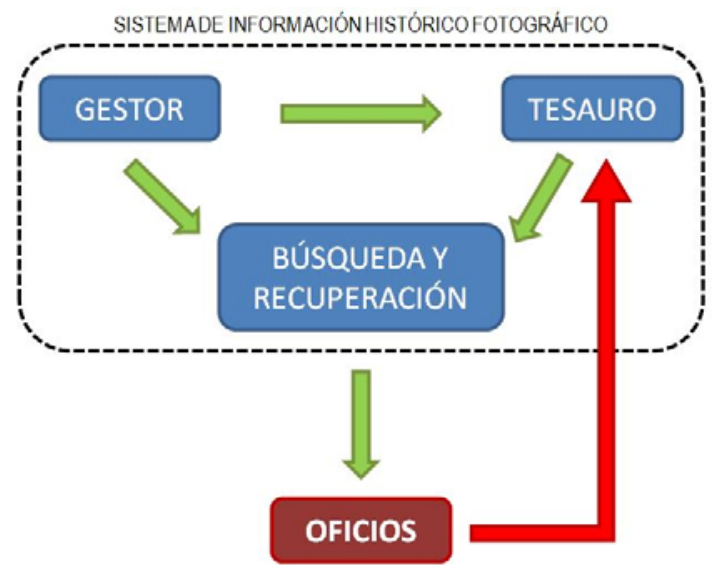

Figura 3. Sistema de información histórico fotográfico (elaboración propia).

A continuación, vemos el ejemplo de una ficha, creada por nosotros, correspondiente a una de las fotografias analizadas (figura 4). En ella se recoge toda la información que se ha podido extraer de la descripción de la imagen.

Ficha
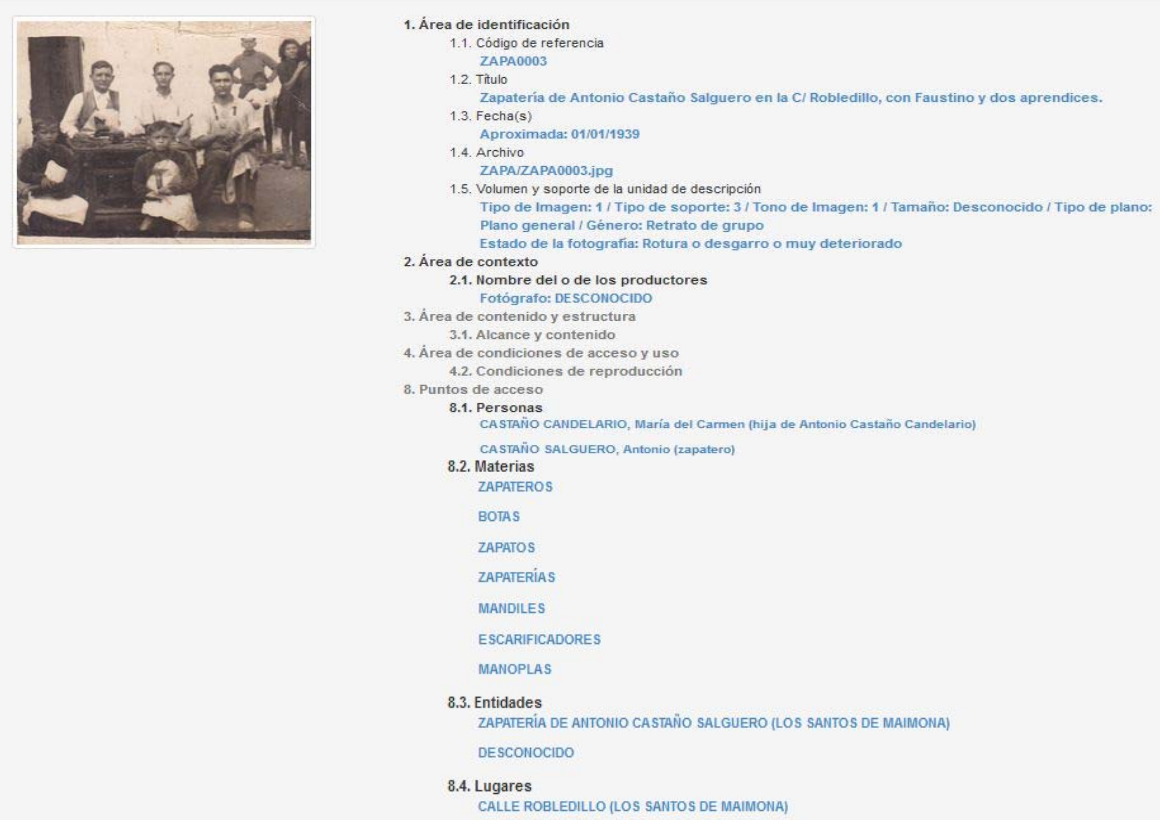

Figura 4. Ficha de una fotografía (elaboración propia). 
Una vez descritas, las imágenes podrán buscarse y visualizarse a través de los descriptores (temáticos, onomásticos, de entidades y de lugar). La figura 5 representa la página de resultados que obtiene el usuario tras realizar una búsqueda. En este caso, se trata de la relación de documentos pertenecientes a la consulta por descriptores temáticos.

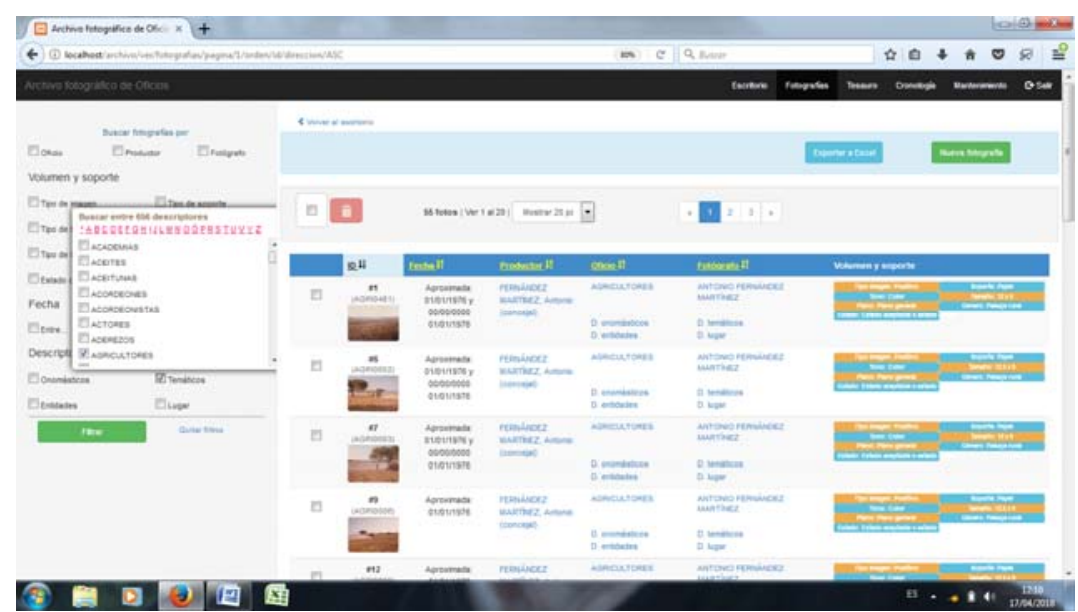

Figura 5. Descriptores de materia (elaboración propia).

En el ejemplo, se aprecia que la interrogación al sistema se ha realizado a partir del descriptor "agricultores". Tal y como muestra la imagen, el gestor arroja un resultado de cincuenta y cinco fotografías relacionadas con este oficio.

Por su parte, la figura 6 representa la búsqueda de fotografías mediante el descriptor onomástico "MURILLO TOVAR, Juan"; en este caso, el gestor indica que sobre esta persona existen ciento doce imágenes de diversa temática.

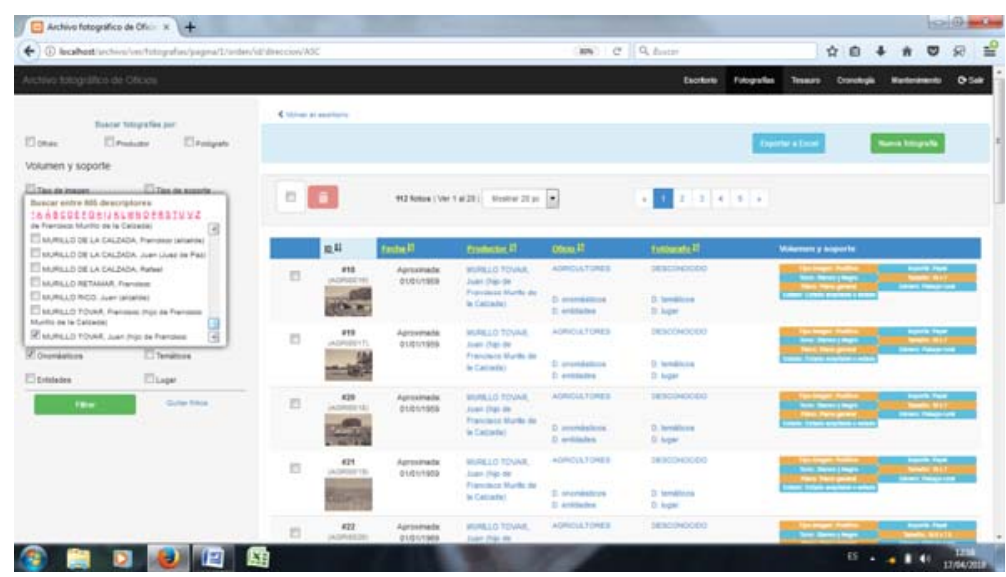

Figura 6. Descriptores onomásticos (elaboración propia). 
Además, al gestor se le ha incorporado un tesauro, que va a permitir realizar las búsquedas y la consecuente recuperación de las fotografías que reflejan los oficios que previamente se han descrito. Contará con términos genéricos, específicos y relacionados, de tal manera que podremos localizar la fotografía que se precise por diferentes vías. A continuación, se muestra una imagen del tesauro (figura 7):

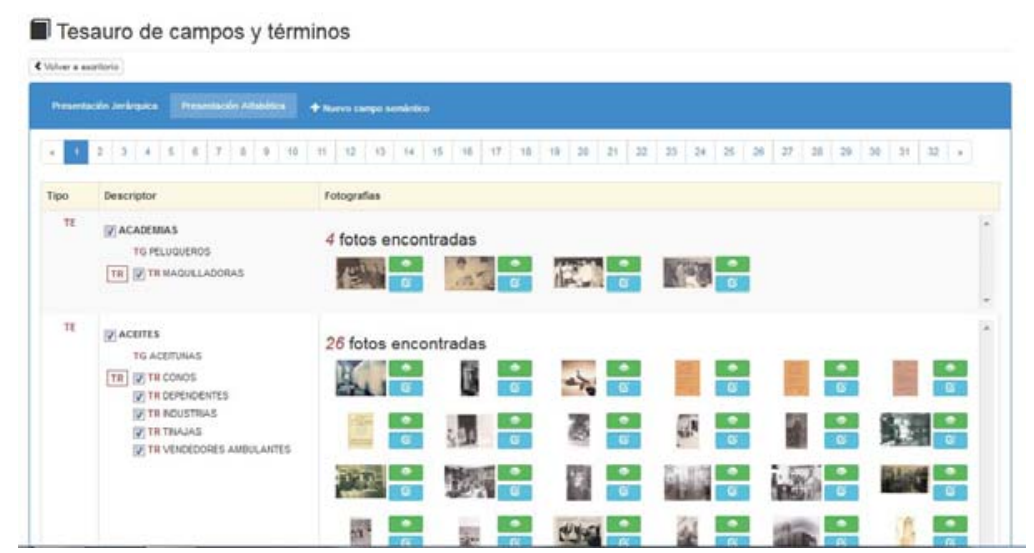

Figura 7. El tesauro (elaboración propia).

El empleo de las tecnologías de la información nos ha permitido trabajar de forma eficiente con el gestor documental, pues permite que nuestro SI pueda ser utilizado por cualquier investigador de una manera intuitiva. En la siguiente figura (figura 8) comprobamos cómo todos los elementos que forman parte de nuestro sistema están perfectamente unificados para facilitar la información que se precise en cada momento. Integramos el tesauro, las fotografías, los buscadores, en definitiva, todas las herramientas de las que hemos hablado en un solo instrumento de búsqueda y análisis de información.

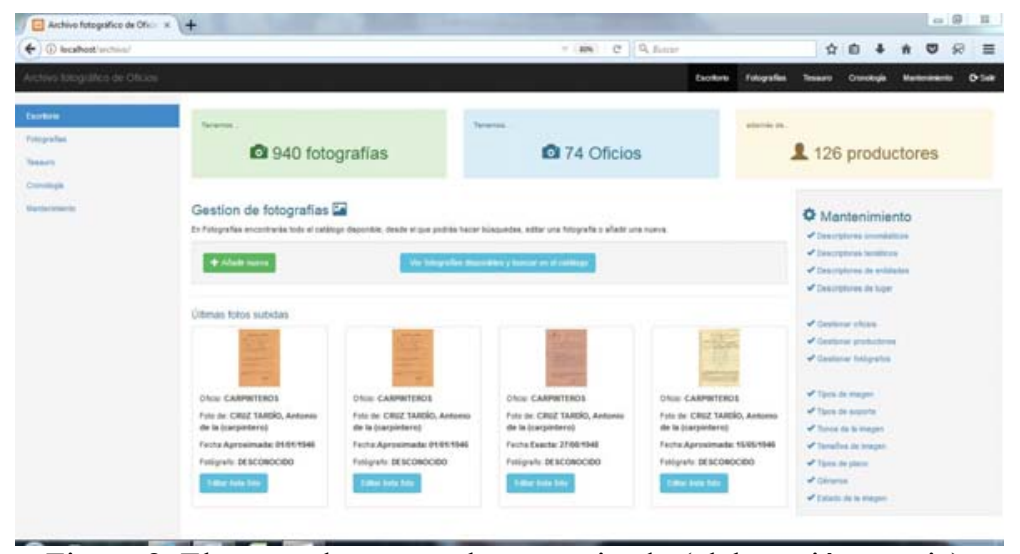

Figura 8. El gestor documental automatizado (elaboración propia).

A través de este artículo, se ha pretendido demostrar que el SIHF permite realizar un análisis de los oficios que se desempeñaban en la localidad de Los 
Santos de Maimona, en una franja de tiempo determinada. Por lo tanto, dicha herramienta podría ser aplicada a cualquier otro tipo de estudio donde el documento base sea una imagen.

\section{Conclusiones}

Siguiendo el hilo argumental de los objetivos propuestos al principio de nuestro trabajo de investigación, son tres las conclusiones obtenidas sobre el análisis de los oficios a través de las fotografías en el s. XX:

1. Hemos logrado recopilar novecientas cuarenta fotografías relacionadas con los oficios que se desarrollaban en la localidad durante el periodo de tiempo establecido. El trabajo de recuperación de esta colección fotográfica ha resultado complejo por las cuestiones que hemos analizado en el apartado de los objetivos. Confirmamos, a su vez, la inexistencia de una política común, tanto a nivel local como regional y autonómica, para el tratamiento de este tipo de documentos, que no están sometidos a criterios archivísticos, sino que son tratados de un modo arbitrario. Por otra parte, el desierto normativo para esta documentación hace que se trabaje sin uniformidad ni criterios estándar, sino de un modo arbitrario.

2. La creación de un sistema de información histórico fotográfico (SIHF) nos ha permitido, la búsqueda y recuperación de la información dentro del corpus documental que hemos elaborado. Debido al gran número de imágenes con las que contamos, esta herramienta informática nos permitirá recuperar la información que precisemos en cada momento.

3. Constatamos que el estudio de la fotografía es base para la confección de la historia local de Los Santos de Maimona, y cómo cada imagen se convierte en una unidad documental para el análisis de la misma. Mediante el análisis de las fotografías, podemos obtener datos que nos permiten la investigación y observación de una parte de nuestro pasado o presente.

La confección de un SIHF resulta ser un método fiable para la búsqueda y recuperación del patrimonio fotográfico, y se confirma, pues, la importancia de la metodología documental para el análisis histórico.

\section{Referencias bibliográficas}

Ballester Olivera, J. M. et al. (2006) Tres miradas distintas: fotografías. (Exposición celebrada en Cáceres, Museo, de junio-agosto 2006). Cáceres, Museo.

Bayod Camarero, A. La fotografía histórica como fuente de información documental. http://docplayer.es/9019719-La-fotografia-historica-como-fuente-de-informaciondocumental.html. [Consulta: 15/6/2016].

Bayod Camarero, A. (2009) La fotografía y su reflejo social. Belmonte (1860-1940). Asociación Cultural “Amigos del Mezquín”, Belmonte (Teruel), p. 544. 
Benavides Solís, J. (1995). Siete enunciados sobre la Teoría General del Patrimonio Cultural. Boletín del Instituto Andaluz del Patrimonio Histórico, $\mathrm{n}^{\mathrm{o}} 12$.

Cano Ramos, J., et al (2014).Extremadura revelada: fotografía histórica y su revisión actual. Gobierno de Extremadura, Consejería de Educación y Cultura.

Castellano Gámez, M.; Sánchez Martínez, J. A. (1996). Apuntes para la gestión del patrimonio histórico desde una perspectiva municipalista. Boletín Informativo del Instituto Andaluz de Patrimonio Histórico, $\mathrm{n}^{\circ} 17$.

Cerdá Días, J. (2000). El archivo municipal y su relación con los ciudadanos. Lligall.

Codina Bonilla, L. (1994). La naturaleza de la recuperación de la información: implicación para el diseño de sistemas de información documentales. IV Jornadas Españolas deDocumentación Automatizada, Gijón.

Díaz Barrado, M. P. (1998). Historia del Tiempo Presente y nuevos soportes para la información. Cuadernos de Historia Contemporánea, 20, 41.

Felicísimo Pérez, Á. M.; Cuarteto Sáez, A. (1999) Extremadura desde el aire: 60 años de evolución del territorio. $<$ https://dehesa.unex.es/handle/10662/7144>. [Consulta: 4/2/201]. Martínez Zamora, María Eulalia et al. Fotografía extremeña contemporánea 1979-1999. (Exposición celebrada en Mérida). Mérida: Editora Regional.

García Marco, F. J. Los Sistemas de información histórica: una nueva frontera en la construcción científica de la historia. <https://dialnet.unirioja.es/descarga/ articulo/2245396.pdf>. [Consulta: 2/2/2017]

Guijo de Granadilla. Cien años de imágenes. Guijo de Granadilla: Ayuntamiento, 2007.

Lacomba, J. A. (2008) La historia local y su importancia. (I Congreso de Historia de Linares, abril). Linares.

Lara López, E. L. (2005). La fotografía como documento histórico-artístico y etnográfico: una epistemología. Revista de Antropología Experimental, 5, 2.

Moreiro Gonzalez, J. A. (1995). Los sistemas de información documental: consideraciones sobre sus características, concepto y funciones. Boletín Millares Carlo, 14, 137.

Muro Castillo, M. (2009). Fotografía en Extremadura hasta 1951. Colección cuadernos populares. Editora Regional Extremeña.

Muro Castillo, M. (2000). La fotografía en Extremadura, 1847 - 1951. Editora Regional Extremeña.

Navarreño Mateo, A.; Pérez Rodríguez, R. (1985). Castillos y fortificaciones en Extremadura. Editora regional de Extremadura.

Pacheco Valero, I. (2003). Una estrategia metodológica para el conocimiento de la identidad cultural.(Tesis en opción al título académico de Master en Ciencias de la Educación Superior en la Mención de Docencia Universitaria e Investigación Educativa, Ciudad de la Habana, enero, 2003). Habana: Universidad de Ciencias de la Educación Superior.

Pinto Molina, M. (1991). Análisis documental. Fundamentos y procedimientos. Madrid: EUDEMA, S.A.

Poves Verde, L. (1998). Estampas para el recuerdo. Los Santos de Maimona: Caja Rural de Extremadura.

Regalado Guareño, A. (2013). Oficios callejeros en Badajoz: décadas 1940 y 1950. Ayuntamiento de Badajoz. Concejalía de Cultura.

Ruiz Rodríguez, A. Á. (1995). Los Sistemas de información histórica: entre la archivística y la historia. Manual de Archivística. Madrid: Síntesis.

Serna, J.; Pons, A. (1993). El ojo de la aguja. ¿De qué hablamos cuando hablamos de microhistoria? Revista Ayer, 12, 131.

Soto Vázquez, J. (2011). La fotografía escolar de Ezequiel Fernández Santana (1915 1938). Los Santos de Maimona, Fundación Maimona. 
Soto Vázquez, J. (2009). Las escuelas públicas de niños en Los Santos de Maimona (1909 1939). La alfabetización escolar. Los Santos de Maimona, Fundación Maimona.

El taller de los hermanos Tinoco. (2007) (Exposición celebrada en Badajoz, Museo de Bellas Artes de Badajoz, del 26-IV-2007 al 26/VI/2007. Badajoz, Indugrafic S. L.

Valle Gastaminza, F. del (1999). Manual de documentación fotográfica. Madrid: Editorial Síntesis. 